B. M. Foss, and The Beginnings of Modern Psychology by W. M. O'Neil is the first of a series "Method and History", edited by the author.

In evaluating these texts, it seems important to consider the kind of reader at which they are aimed: whether they would be suitable for a general reader, a person knowing some psychology, or a specialist. C. E. Gathercole's book, for example, seems to be aimed at peoplo who know some psychology but are not specialists in this particular branch. At the same time, it will probably also be of interest to elinical psychologists. The author discusses various aspects of the work of the clinical psychologist, including topics such as the relationship of psychologist and psychiatrist, the attitudes of patients towards the psychologist, and the place of research in clinical work. These are questions which are part of the oral tradition, so to speak, of clinical psychology and it is pleasant to see them at last set down on paper. The author's style is clear and witty; he has no hesitation in expressing his own views forcefully and there is much in this book which ought to provoke clinical psychologists to reconsider their aims and methods.

On the other hand, it is hard to visualize the kind of reader for which G. A. Talland's book is suitable. By itself, the plan of the book is promising. The author begins by discussing theories of memory and learning, both psychological and biological. He then deals with disorders of these processes, looking at them from the point of view of both the diagnostic categories in which they are found and also the dysfunction involved. Nor can exception be taken to the content in itself: the discussion of the theories and of the disorders is impartial and scholarly. The author also continually makes elear how complex are the procasses involved and how poorly we understand them: a salutary corrective to the view that memory is just a matter of conditioned reflexes and rote learning. It is a pity therefore that the book seems unlikely to appeal to either the psychologist or the layman. For the psychologist, the evidence on which the author relies is not presented in enough detail to make independent evaluation possible, nor is any striking new viewpoint put forward. On the other hand, it is liksly that the layman will be confused by this book: he is not provided with any very satisfactory framework into which to fit his new knowledge, and many difficult concepts, such as information theory, are inadequately explained. Although the author provides many illustrative anecdotes, their relevance is sometimes not obvious, and they do not appear to clarify the point in question.

D. R. Savage's Psychometric Assessment of the Individual Child seems to run into similar problems as regards readership. The author starts with a brief account of the theory of intelligence testing and ends with an appendix dealing with some common statistical concepts: these sections are obviously aimed at the non-psychologist, although it is likely that he would find them rathor too brief to bo of much help. The bulk of the book, however, consists of brief descriptions and evaluations of various tests used in the assessment of children, together with some examples of how they might be used in clinical practice. The review is a comprehensive one and the comments for the most part fair: the only major criticism which might be levelled at the content of these sections is that they present a rather pedestrian picture of the psychologist's contribution to this field. It is again difficult, however, to see for whom such an account is suitable. Without knowledge of child psychiatry and of the theory of testing, and without some acquaintance with the kind of test materials involved, such a list of tests would be rather meaningless. On the other hand, like G. A. Talland, the present author does not present enough evidence in support of his evaluations of the tests to make thom of interest to the professional psychologist.

The fourth book, The Beginnings of Modern Psychology, differs from the other throe both in its subject matter and aim. The following monographs in this series will deal with contemporary movemonts in modorn psychology and this present one is intendod, in the author's words, to form "a backdrop" to them. This backdrop is formed by historical accounts of the main movements within psychology and of the contributions of philosophy, physiology and medical psychology. As this is presumably intended to be a kind of reference book to be used in close conjunction with the later volumes, it is difficult to evaluate it on its own, except to say that the author, with the limited space available to him, follows the wise course of concentrating on the relationship between the theories of different workers, of placing them in their context, rather than expounding their content, which will presumably be done in these later volumes.

On the whole, then, these four books represent an interesting start to a new kind of series of psychological texts. It seems likely, however, that the problem which most of them have run into, namely that of aiming consistently at one kind of reader, will also be encountered by many of the later volumes. VALERIE WAJKEER

\section{MONKEY BRAIN}

\section{A Stereotaxic Atlas of the Brain of the Cebus Monkey (Cebus apella)}

By Sohan L. Manocha, Totada R. Shantha and Geoffrey H. Bourno. Pp. 97. (Clarendon Press: Oxford; Oxford University Press: London, December 1968.) $45 s$.

This is a well produced and reliable stereotaxic atlas of the brain of a monkey which is becoming important as an experimental animal. In the United States at least, it seems likely to replace the rhesus monkey, which, as the authors state, is "increasingly difficult and expensive to import from India". The atlas is of the Horsley-Clarke coordinate type with the antero-posterior zero plane, perpendicular to the Frankfurt plane, at the level of a transverse line through the centres of the external auditory meati.

Thirty-six coronal levels are illustrated extending from $19.5 \mathrm{~mm}$ anterior to $9.0 \mathrm{~mm}$ posterior to the anteroposterior zero plane. Two sections are shown from each, one stained for myelinated fibres and the other for cells. The regions shown in the series are the greater part of the corpus striatum, the amygdala and part of the hippocampal formation in the cerebral hemispheres, the whole of the diencephalon, the midbrain, corebellum and medulla oblongata. The photographic reproduction is reasonably good and the labelling quite detailed; individual nuclei in such regions as the amygdala and the thalamus are marked and it is a great convenionce that the abbreviations used are listed alphabetically at the side of each illustration.

The text gives a short but useful account of the species and of the external morphology of the brain; the latter could have been more adequately illustrated with advantage. Tho technical methods used to ensuro reliability of stereotaxic coordinates and plane of section are described in detail and appear to have been carried out with great care and to be entirely adequate. A bibliography and an index in the form of a list of all the structures illustrated with their stereotaxic levels are provided. In the index structures are listed in the alphabetical order of the abbreviations used, so that, unless the abbreviation is known, it is difficult to discover the level of any particular structure.

There is no doubt of the value of this work for the planning of experimental neuroanatomical and neurophysiological investigations. It will also be of value to advanced students of neuroanatomy in giving clear and well labelled illustrations of important parts of a primate brain.
F. GOLDBX 